\title{
Rezension zu: Ingemar König, Die Spätantike (2007)
}

\author{
Alexander Heising
}

Im neuesten Band der in der Wissenschaftlichen Buchgesellschaft Darmstadt erscheinenden Reihe „Geschichte kompakt"“1 bietet I. König eine notwendigerweise knapp gehaltene Darstellung des Zeitraums vom Tode Konstantins 337 n. Chr. bis zur Absetzung des Romulus Augustulus durch Odoaker und damit dem faktischen Ende des Westkaisertums im Jahr $476 \mathrm{n}$. Chr.

Die editorischen Gestaltungsprinzipien sind dem Konzept der Reihe geschuldet: Jedem Kapitel ist eine kurze Zeittafel vorangestellt, Stichworte am Rand gliedern den Text. Auf Einzelbelege wird in der Regel verzichtet, wenige ausgewählte Quellen sind durch graue Felder hervorgehoben und im Volltext wiedergegeben. Ein kurzes Glossarium, ein nach Themen gegliedertes, sparsam kommentiertes Quellenund Literaturverzeichnis sowie ein Register beschließen den Band. Die Struktureigenheiten der Reihe sind schon bei Besprechungen früherer Titel kritisiert worden. ${ }^{2}$ Insbesondere die Entscheidung der Herausgeber, aufgrund eines besseren Leseflusses von Quellenbelegen in Fuß- oder Endnoten abzusehen, mag zwar mit dem allgemeinen Ziel ,einer anschaulichen Vermittlung von Basiswissen für Studierende, Lehrende und historisch Interessierte" begründet sein, schränkt den Wert der Reihe jedoch gerade für die genannten Rezipienten erheblich ein. Dieses Manko ist aber nicht dem Autor anzulasten.

I. König war bis zu seiner Emeritierung außerplanmäßiger Professor für Alte Geschichte an der Universität Trier und hat sich im Bereich der Spätantike mehrfach mit dem Herrschaftssystem der Tetrachien ${ }^{3}$ und der Zeit Theoderichs des Großen ${ }^{4}$ auseinandergesetzt. Durch seine Schriften zum „Römischen Staat“ und seiner bereits in zweiter Auflage erschienenen „Kleinen römischen Geschichte“ als hervorragender Kenner der römischen Historie ,ab urbe condita bis zum Untergang des Ostgotenreiches" ausgewiesen", war er prädestiniert dafür, im Rahmen dieser Reihe einen zusammenfassenden Überblick über die Spätantike beizusteuern. Zuletzt hat er sich in einer populärwissenschaftlichen Schrift mit dem Alltagsleben der Römer auseinandergesetzt. ${ }^{6}$

\footnotetext{
${ }^{1}$ In der Reihe sind noch weitere Titel zum Thema spätrömische Kaiserzeit erschienen: K. Piepenbrink, Antike und Christentum (Darmstadt 2007). - K. Piepenbrink, Konstantin der Große und seine Zeit ${ }^{2}$ (Darmstadt 2007).

${ }^{2}$ Vgl. z. B. Udo Hartmann: Rezension zu: Sommer, Michael: Die Soldatenkaiser. Darmstadt 2004. In: H-Soz-u-Kult, 06.04.2004, <http://hsozkult.geschichte.hu-berlin.de/rezensionen/2004-2-014>.

${ }^{3}$ I. König, Die Berufung des Constantius Chlorus und des Galerius zu den Caesaren; Gedanken zur Entstehung der Ersten Tetrarchie. Chiron 4, 1974, 567-576. - Ders., Lactanz und das "System" der Tetrachie. Labeo 32, 1986, 180-193. - Ders., Origo Constantini. Anonymus Valesianus: Teil I, Text und Kommentar. Trierer Historische Forschungen 11 (Trier 1987).

${ }^{4}$ I. König, Theoderich d.Gr. und die Kirche S. Stefano zu Verona. Trierer Theologische Zeitschrift 95, 1986, 132-142. - Ders., Die Herrschaftsbestätigung Theoderichs des Großen durch die Goten im Jahre 493. Ein spätantikes Rechtsproblem. In: Studien zur Geschichte und Kultur des Altertums I.8 = "E fontibus haurire" Festschrift für H. Chantraine (Paderborn 1994) 147-161. - Ders., Aus der Zeit Theoderichs des Großen. Einleitung, Text, Übersetzung und Kommentar einer anonymen Quelle = Theodericiana, primum ab Henrico Valesio edita, denuo edita, translata, adnotationibus exegeticis critisque instructa. Texte zur Forschung 69 (Darmstadt 1997).

${ }^{5}$ I. König, Der römische Staat. Teil I: Die Republik (Stuttgart 1992). - Ders., Der römische Staat. Teil II: Die Kaiserzeit (Stuttgart 1997). - Ders., Kleine römische Geschichte. (Stuttgart 2001).

${ }^{6}$ I. König, Vita Romana. Vom täglichen Leben im alten Rom (Stuttgart 2004).
} 
Die Komplexität der gut 150 Jahre umfassenden Epoche „Spätantike“ zwingt König zu einer Beschränkung auf die politischen und kirchlichen Entwicklungen; die Sozial- und Wirtschaftsgeschichte sowie der Bereich der Kunst bleiben deshalb weitgehend ausgespart. An geeigneten Stellen wird die ereignisgeschichtliche Darstellung aber immer wieder durch kurze Exkurse zu bestimmten Themen (z. B. zur Philosophie und Rhetorik bei Julian, S. 19) unterbrochen, so daß König der Gefahr entgeht, bei einer reinen Aneinanderreihung von historischen Begebenheiten in eine Nacherzählung von Aurelius Victor, Eutrop oder Ammianus Marcellinus zu verfallen.

Der Text ist in fünf chronologische Abschnitte unterteilt. Im ersten Kapitel „Die Erben Constantin des Großen oder Die Christianisierung des römischen Reiches“ (S. 1-40) wechseln sich ereignis- und kirchengeschichtliche Darstellungen ab. Am Anfang steht eine durchaus kritische Bilanz der Herrschaftsleistung des Konstantin, die gerade im „Konstantin-Jahr“ 2007 mit seinen großen internationalen Ausstellungen erfrischend wirkt. $^{7}$ Der pointierten Analyse des Konflikts der Konstantinssöhne um die Nachfolge schließt sich ein kurzer Abschnitt zum beginnenden Schisma zwischen „römischer" und „orthodoxer" Kirche an, deren Spaltung im Konzil von Serdica 342 n. Chr. angelegt war. Im Zusammenhang mit der Episode der Magnentius-Usurpation geht König dann auf die prekäre militärische Lage im Westen des Reiches ein, die auch im folgenden Zeitabschnitt des Constantius II. eine große Rolle spielt. Den sich abzeichnenden, durch den Einfall Schapurs II. 359 n. Chr. offen ausbrechenden Perserkrieg nimmt König zum Anlaß, dem Leser schlaglichtartig eine spätantike Kaiserkorrespondenz vorzustellen (S. 25f.). Eine ausführliche Würdigung erfährt die Regierung Julians, die, obwohl sie „keine drei Jahre währte, nicht als ephemer gewertet werden“ kann. Insbesondere „sein Engagement für die Philosophie und das Heidentum“ hätte „zu einer geistigen Renaissance des späten Hellenismus“ geführt (S. 38). Ein Exkurs zum spätantiken Herrscherideal beschließt das Kapitel.

Der folgende Abschnitt behandelt die valentinianische und theodosianische Dynastie (S. 41-72), in der König vor allem die Außen- sowie die Innen- bzw. Kirchenpolitik in den Vordergrund rückt. So machte die äußere Bedrohung im Westen und Osten nicht nur eine Doppelherrschaft des Valentinian/Valens notwendig, König weist auch auf den zunehmenden Einfluß germanischer Offiziere auf die militärische wie politische Entwicklung des Reiches hin. Ein eigenes Unterkapiteln ist den Hunnen und Goten gewidmet: Das erstmalige Erscheinen der Reitervölker war einer der Auslöser für den Untergang des Ostgotenreiches 375 n. Chr. und führte letztlich auch zur Schlacht bei Adrianopel 378 n. Chr., bei der eine vor den Hunnen zurückweichende, ostgermanische Allianz den Römern eine katastrophale Niederlage bereitete.

Die kirchengeschichtlichen Ereignisse sind laut König durch zunehmende Konflikte zwischen Nicaenern und Arianern geprägt, so z. B. in der Episode der doppelten Papstwahl in Rom $366 \mathrm{n}$. Chr., die zu langen, blutigen Auseinandersetzungen führte und die Macht einzelner Bischöfe, u.a. in Rom, Mailand und Tours stärkte (Unterkapitel „Die Kirche im Westen“, S. 49-51). Nicht als eigener Abschnitt ausgewiesen ist die glaubenspolitische Entwicklung unter Theodosius, die aufgrund ihrer Weichenstellung für die Zukunft in einem separaten Kapitel hätte behandelt werden müssen. Mit seinem Edikt Cunctos populos 380 n. Chr. erklärte Theodosius

\footnotetext{
${ }^{7}$ A. Donati/G. Gentili (Hrsg.), Costantino il Grande. La civiltà antica al bivio tra Occidente e Oriente (Rimini 2005). - E. Hartley u.a. (Hrsg.), Constantine the Great. York's Roman Emperor (York 2006). A. Demandt/J. Engemann (Hrsg.), Konstantin der Grosse. Ausstellungskatalog Trier (Mainz 2007).
} 
immerhin das katholische Christentum zur alleinigen Staatsreligion und manifestierte so die Spaltung zwischen einer West- und einer Ostkirche. Abschließend unternimmt König den „Versuch einer Charakterisierung“ des vierten Jahrhunderts (S. 69 -72): Als wichtige Faktoren stellt er die Abfolge von Dynastien (wenn auch nicht im modernen Sinne) heraus, ferner die Einbindung foederierter gentes an den Reichsgrenzen, die Christianisierung des Reiches und damit verbunden den Rückzug des Heidentums sowie den Glaubensstreit der Arianer und Nicaener als Bedrohung der Reichseinheit.

Das dritte Kapitel „Das Zeitalter der Reichsteilung“ (S. 73-94) leitet König mit dem wichtigen Hinweis ein, daß die Teilung 395 n. Chr. weder geplant war, noch im damaligen Verständnis die Bedeutung hatte, die ihr heute oft zugewiesen wird. Sie könne lediglich als eine Fortsetzung der Aufgabenteilung innerhalb der „Dynastien“ gesehen werden. Nicht zuletzt aufgrund der Rolle eines „rangersten“ Augustus muß laut König unbedingt unterschieden werden ,zwischen der ideologisch bewahrten Reichseinheit und der realen Entwicklung, die schließlich zum Verlust des Westen führte." (S. 73). Im weiteren Verlauf des Textes (der aufgrund der zunehmend dürftigeren Quellen auch knapper ausfällt als die Geschehnisse des 4. Jhs.) zeigt sich, dass im Hinblick auf diese Zeit Ereignisgeschichte weitgehend Personengeschichte ist: Die historisch wirksamen Personen sind u. a. die beiden Augusti Arcadius und Honorius, die Heermeister Stilicho und Alarich, dem unter dem bezeichnenden Titel „Das ,Problem Alarich““ ein eigener Abschnitt gewidmet ist, die Augustae Pulcheria und Galla Placidia, sowie die in den 440er und Anfang der 450er-Jahren beherrschenden Gegenspieler Aetius und Attila. In der das Kapitel abschließenden Wertung Königs „war der Zerfall der Römerherrschaft nur durch die Fiktion aufzuhalten, dass ein foedus die kaiserliche Autorität und damit die Integrität des römischen Territoriums wahre. Die Aufgabe der Heermeister bestand vor allem darin, mit fremdstämmigen Truppen die foederierten gentes zu ihren Verpflichtungen, die Grenzen des Reiches zu verteidigen, zu zwingen“ (S. 90). Ein weiteres Problem bestand darin, daß die angesiedelten Germanen und die Romanen weiter auseinander drifteten, nicht zuletzt aufgrund der unterschiedlichen Glaubensbekenntnisse.

Das vierte Kapitel behandelt „,das Ende des „Weströmischen Reiches“, obwohl es mit dem Codex Theodosianus eingeleitet wird, jener Gesetzessammlung, die als Dokument der juristischen Reichseinheit auch noch in den späteren germanischen Codices weiter Bestand haben sollte. Königs Darstellung reicht bis zur selten behandelten Herrschaft des Odoaker 476-493 n.Chr. und legt damit eine ähnliche Grenze fest wie Demandt im Handbuch der Altertumswissenschaft. ${ }^{8}$ König schließt sich mit den Worten „Autoritätskämpfe im Innern, politische Auseinandersetzungen mit Ostrom schwächten das westliche Kaisertum ebenso wie das egoistische Verhalten der Heermeister" dem allgemeinen Urteil der Geschichtswissenschaft über diese Endphase weitgehend an (S. 99).

Das letzte, sehr knapp gehaltene Kapitel umfasst „Untergang und Weiterleben“. Als Ausblick gedacht, ist es nicht wie die anderen Kapitel chronologisch gegliedert. Vielmehr geht König hier noch kurz auf die bisher weitgehend vernachlässigten sozialen und wirtschaftlichen Entwicklungen ein, die zu einem erheblichen Teil mit zum Verlust des Westens an die Germanenreiche beigetragen haben. Diesen Verlust wertet König als eine „Identitätskrise größten

\footnotetext{
${ }^{8}$ A. Demandt, Die Spätantike. Römische Geschichte von Diocletian bis Justinian $284-565$ n. Chr. Handbuch der Altertumswissenschaft III, 6 (München 1989).
} 
Ausmaßes“, war doch „Rom in den Augen der Reichsbewohner in Ost und West der Mittelpunkt des Imperiums geblieben“. In diesem Sinn will König auch die folgende Restaurationspolitik Justinians in Ostrom nicht ,als Auswuchs eines ,byzantinischen Imperialismus'“, sondern als Versuch, die Identität des [gesamten] Imperiums zurückzugewinnen“ verstanden wissen.

Dem Rezensenten sind nur wenige Unstimmigkeiten aufgefallen: So bezieht sich die Ammian-Stelle 17, 8, 3 nicht auf Constans, sondern auf Julian (S. 8) ${ }^{9}$, S. 10 soll es anstatt „Apostelfüsten“ Peter und Paul sicher ,-fürsten“ heißen, auf S. 116 fehlt ein Hinweis auf die Ersterscheinung des „Klassikers“ von E. Gibbon „Verfall und Untergang des römischen Imperiums“ 1776-1788. Zu diskutieren ist die Bedeutung des oft zitierten Epochenjahres 406/407 (S. 79 f.), dessen Auswirkungen heute - zumindest von Archäologenseite - eher gering beurteilt werden ${ }^{10}$; die Lokalisierung der Rheinüberquerung von Vandalen und Alanen „bei Kaub“ ist dem Rezensenten neu und aus der betreffenden Quelle (einem Hieronymus-Brief) nicht abzuleiten.

Ungeachtet dieser Marginalien ist König mit der „Spätantike“ eine gut lesbare Einführung gelungen, die als Einstieg ins Thema und zur schnellen Information bestens geeignet ist. Der knapp bemessene Umfang der Reihe führt naturgemäß zu inhaltlichen Beschränkungen.

\footnotetext{
${ }^{9}$ Vgl. K. H. Lenz, Germanische Siedlungen des 3. bis 5. Jahrhunderts n. Chr. in Gallien. Schriftliche Überlieferung und archäologische Befunde. Ber. RGK 86, 2005, 349-444, bes. 361. 367 Anm. 101.

${ }^{10}$ Vgl. M. Grünewald, Burgunden: Ein unsichtbares Volk? In: H. Hinkel (Hrsg.), Nibelungen Schnipsel. Neues vom alten Epos zwischen Mainz und Worms (Mainz 2004) 119-142, bes. 126-128.
} 